Journal of Research in Technical Careers

May 2020, Vol. 4, No. 1.

(C) Author(s)

\title{
Factors that Influence Persistence of Biology Majors at a Hispanic-Serving Institution
}

\author{
Shetay Ashford-Hanserd, Kristy L. Daniel, Dana M. García, Jenn L. Idema \\ Texas State University
}

\begin{abstract}
To promote diversity within the science, technology, engineering, and mathematics (STEM) workforce, we must identify factors that influence or hinder historically underrepresented minority (URM) students' persistence to degrees in STEM. We documented potential factors that influence students' persistence in an undergraduate biology program and created a 14-item, Likert-scale instrument. We recruited 137 undergraduate biology majors at a Hispanic-serving institution in Texas to report which factors they found influential in their decision to remain enrolled in their degree programs. We used a modified social cognitive career theory model of career choice to guide interpretation of the reported influences and identify patterns in responses. We documented three highly influential factors for all students: personal motivation, potential learning experiences, and job opportunities with the job opportunities showing a significant difference $(\mathrm{P}=0.036)$ between White and URM student groups. We also found a trend $(\mathrm{P}=0.056)$ indicating White students were more influenced by role models and mentors than URM students. Our findings suggest that personal motivation and potential job opportunities are the most influential factors driving students to seek educational opportunities that could lead to STEM careers. However, access to a diverse pool of role models also has the potential to provide positive impacts on student persistence in STEM.
\end{abstract}

Keywords: Hispanic-serving institution, persistence in STEM, STEM retention, undergraduate biology majors, underrepresented minority students

As the United States strives to maintain a global leadership role in science, technology, engineering, and mathematics (STEM), the demand for a robust, innovative STEM workforce continues to rise. Higher education plays a pivotal role in the creation of such a workforce. In the effort to drive innovation, increased focus has been placed on the inclusion and retention of traditionally underrepresented minority students in STEM education (Covington, Chavis, \& Perry, 2017). Based on the proportion of undergraduate STEM degrees awarded to Whites and members of underrepresented minority groups (i.e., African Americans, Hispanic/Latinos, Asian/Pacific Islander, and Native Americans) over the last 15 years, they account for less than $25 \%$ of the undergraduate STEM degrees awarded in the United States (National Science Board, 2015). The disparity between underrepresented minorities and their White counterparts becomes even greater at the graduate level (Strayhorn, 2010) with underrepresented minorities holding only $29.8 \%$ of

(i) $\odot$ Creative Commons CC-BY-NC-ND: This article is distributed under the terms of the Creative Commons Attribution 4.0 License (http://creativecommons.org/licenses/by/4.0/) which allows others to download your works and share them with others as long as they credit you, but they can't change them in any way or use them commercially. 
Journal of Research in Technical Careers

doctoral degrees in life or physical sciences or engineering (Linley \& George-Jackson, 2013). The aim for this study was to identify factors that influence persistence among students in STEM degrees, and related differences between underrepresented minority and White students. Understanding these factors is vital for creating a more diverse STEM workforce.

Prior research has identified a multitude of factors that can negatively impact underrepresented minorities' persistence in STEM programs. These include discrimination (Haynes \& Jacobson, 2015; Scott \& Martin, 2014), negative perceptions and stereotypes, (Strayhorn, 2010) and lack of self-efficacy, which denotes the confidence and knowledge to pursue careers in STEM fields (Haynes \& Jacobson, 2015; Scott \& Martin, 2014). Additionally, the willingness of underrepresented minority students to pursue a STEM major is affected by the overall financial burdens associated with higher education (Haynes \& Jacobson, 2015). Underrepresented minority students also encounter negative interactions with their peers both inside and out of educational institutions, and these interactions can affect their decision to enroll or stay enrolled in a STEM program (Strayhorn, 2010). Underrepresented minority students tend to enroll in postsecondary STEM programs at much lower rates than their White peers due to a lack of support and role models with whom they can relate (Strayhorn, 2010). The mentoring received by underrepresented minority students from faculty and staff with whom they can relate is important as it contributes positively to continued enrollment in STEM degrees and students' persistence into STEM careers (Samuels \& Seymour, 2015). Existing research has focused on students' decisions to enroll in undergraduate STEM programs; however, few studies have focused on the contributing factors that influence students' decisions to persist in these programs (Lancaster \& Yonghong, 2017; Peralta, Caspary, \& Boothe, 2013). Therefore, understanding which factors influence undergraduate STEM majors' decisions to persist in STEM degrees is essential for the development of strategies and programs that help keep individuals, especially underrepresented minorities, in STEM. As part of a larger study designed to evaluate factors that influence students to pursue and persist in STEM degree programs, this pilot study focused on undergraduate biology majors at a Hispanic-serving institution (HSI) in Texas and compared the rating of importance these factors had on underrepresented minority and White students' decisions to persist in a biology degree.

\section{Theoretical Framework}

According to social cognitive career theory, the primary factors that influence students' decisions to enroll and remain enrolled in STEM majors are pre-college experiences, self-efficacy, outcome expectations, and interest (Lent, Brown, \& Hackett, 1994). We used a modified social cognitive career theory model of career choice (Lent, Lopez, Sheu, \& Lopez, 2011) that included factors related to social supports and barriers that influence biology students' decisions to persist in their program. 


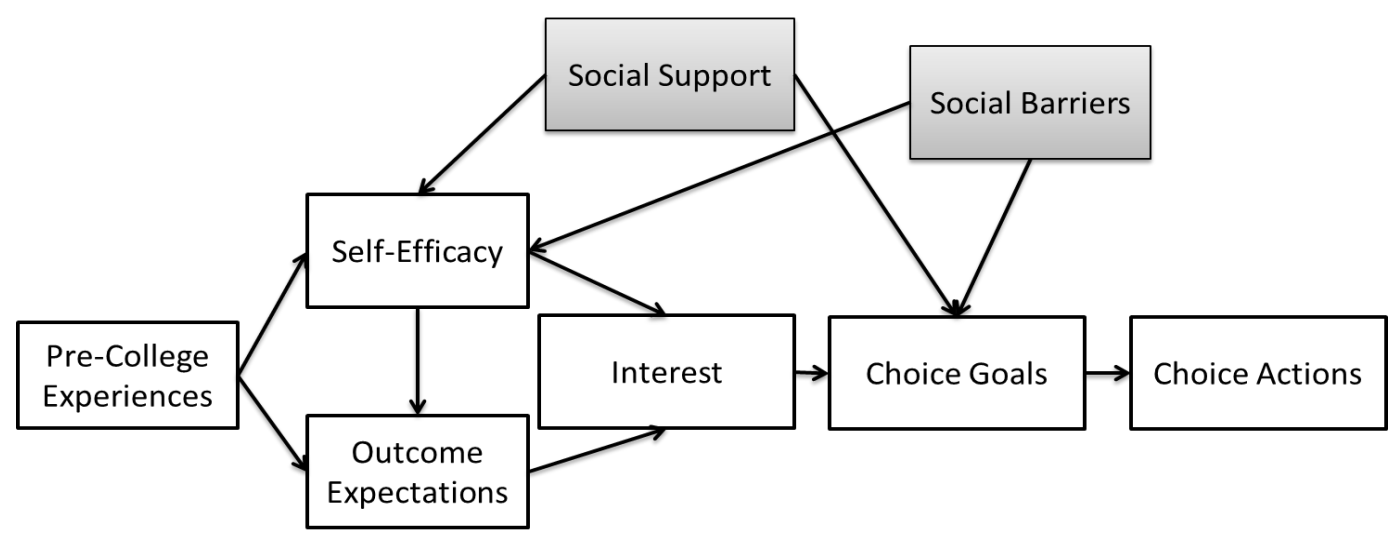

Figure 1. Modified Social Cognitive Career Theory - Model of Career Choice (Lent et al., 1994; Lent et al., 2011).

The career choice model (Figure 1) is conceptually represented into two processes: "the expression of a primary choice goal from among one's major career interests" and "actions designed to implement the choice (e.g. enrolling in a particular training program or academic major)" (Lent et al., 1994, p. 94). This framework illustrates that students' career interests are influenced by their self-efficacy and outcome expectations, which in turn influence their choice goals and ultimately their choice actions. As Figure 1 depicts, this study uses a modified career choice model to describe the relationships between career choice goals and career choice actions; this model represents the process of STEM majors choosing to remain enrolled or persist in undergraduate STEM education. For the purpose of this pilot study, we focus on choice actions - factors that influence students' decisions to persist in a biology major.

\section{Factors that Influence Students' Decisions to Persist in STEM}

To understand the factors that contributed to the persistence of underrepresented minority students in the STEM education pipeline, from kindergarten to graduation from a STEM baccalaureate degree program (i.e., K-16), we conducted a review of the recent literature. In the literature, we identified 11 main factors that contribute to the persistence of underrepresented minority students in STEM majors. These factors include discrimination, race/ethnicity stereotypes, gender stereotypes, microaggressions, family factors, role models and mentors, peer support, self-efficacy, financial factors, sense of belonging, and commitment to diversity.

Discrimination. Underrepresented minority students are most likely to make choice goals and actions based on racial or ethnic discrimination (Haynes \& Jacobson, 2015). These choices are largely influenced by negative perceptions and stereotypes 
towards underrepresented minorities (Strayhorn, 2010). Students that experience more discrimination tend to rate themselves as having lower self-efficacy in subjects such as mathematics, science, general academic skills, as well as lower general self-efficacy (Hall, Nishina, \& Lewis, 2017). This lack of self-efficacy in skills and subjects necessary for success in STEM majors contributes to many underrepresented minority students' decisions to persist in the field. Byars-Winston (2013) found that having a more diverse peer group can help reduce these feelings of low self-efficacy due to discrimination, as well as positively influence a student's decision to pursue a STEM major.

Race and Ethnicity Stereotypes. Negative stereotypes have been identified as one of the barriers that women, African Americans, and numerous other underrepresented minorities encounter while pursuing a STEM degree, particularly African American males (Samuels \& Seymour, 2015; Strayhorn, 2010). For instance, African Americans and Latinos may be negatively perceived by their faculty members or peers (Samuels \& Seymour, 2015). These negative perceptions are often perpetuated by ideas that African American males are dangerous or lazy while African American women are seen as mothers and helpers, which further marginalizes underrepresented minority students. Robinson, McGee, Bentley, Houston, and Botchway (2016) found that African Americans felt more marginalized than Latinos and Asian Americans. Moreover, Asians felt more like impostors than other underrepresented minority students. As a consequence of not being able to fit the established stereotypes that exist in science, underrepresented minority students fail to integrate and subsequently may develop a sense of discomfort (Brown et al., 2016). Furthermore, Brown et al. (2016) observed that a predominance of stereotypes inside the scientific community may cause feelings of alienation due to perceived microaggressions. In some STEM careers, such as computing, the geek stereotype (Whitney, Gammal, Gee, Mahoney, \& Simard, 2013), which is often associated with individuals who are highly intelligent and work long hours, is most prevalent. Some youth are deterred from pursuing a STEM career to avoid this lifestyle and being labeled as a "geek."

Gender Stereotypes. Although our study is focused on underrepresented minorities, White women face negative stereotypes and biases similar to underrepresented minority students. White women are often stereotyped by both male and female faculty and staff (Byars-Winston, 2013). African American women experience less gender-based STEM stereotypes than White women. Additionally, African American women in doctoral programs have had to manage aggressions and other negative behaviors (McPherson, 2017). Nonetheless, large percentages of both White and African American women perceived gender biases in STEM fields (O'Brien, Blodorn, Adams, Garcia, \& Hammer (2015), particularly more than men (Haynes \& Jacobson, 2015). These stereotypes regarding women persist beyond an academic setting, extending into the STEM workforce. Like the geek stereotype, gender stereotypes in the workplace favor masculine qualities, putting women at a disadvantage and encouraging people of both sexes to be more aggressive (Whitney et al., 2013). 
Microaggressions. Another subtle form of aggression and discrimination is microinsults or microaggressions, which consist of brief, repetitive interactions that send a negative message that is indirect and vague (Haynes \& Jacobson, 2015). In their study of undergraduate and graduate underrepresented minority students considering careers in natural resources, Haynes and Jacobson (2015) found that $57 \%$ of participants experienced some type of microaggression: $22 \%$ related to gender biases (p. 176) and $35 \%$ related to race/ethnicity biases (p. 176). In many situations, respondents did not use these precise terms, but described a situation or experience that fit the definition of these terms (Haynes \& Jacobson, 2015). Alexander and Hermann (2016) propose that racial microaggressions may seem normal for both victims and perpetrators at all levels in educational institutions. For example, females and African Americans may feel excluded from activities, which may cause feelings of invisibility and hypervisibility (Robinson et al., 2016).

Family Factors. Family members play a key role in influencing and motivating students to pursue careers in STEM. Moakler and Kim (2014) found that children with parents involved in STEM fields were one and a half times more likely to pursue STEMrelated career fields. Clearly, parents play a meaningful role in influencing their children's decisions to enroll in STEM; parents and close family members with jobs in STEM fields work as mentors and guides throughout the process. For example, most engineering students have at least one supportive family member that exposed them to engineering and encouraged them to pursue it (DeCuir-Gunby, Grant, \& Gregory, 2013). Stokes, Levine, and Flessa (2015) concluded that parents and family members have a direct influence on students' positive attitudes and future decisions to enroll in geoscience programs and possibly other STEM majors.

Role Models and Mentors. According to Lancaster and Yonghong (2017), mentorship can be formal or informal. Furthermore, strong role models can counteract the negative effects of stereotypes (Whitney et al., 2013). As informal mentors and role models, teachers and professors possess the skills necessary for students to learn and gain experience to successfully pursue a STEM major (Gasman, Nguyen, Conrad, Lundenberg, \& Commodore, 2017). To inspire and foster a diverse student population, underrepresented minority professors are necessary in STEM programs (Basile \& Murray, 2015). Therefore, diversity in school faculty is critical to prepare and inspire young African American and Latino students to become STEM professionals (Basile \& Murray, 2015). This conclusion is corroborated by Scott, Taylor, and Palmer (2013) and by Kachchaf, Ko, Hodari, and Ong (2015), studies in which African American students articulated the necessity of likeminded mentors and role models in their areas of interest. African American students felt alienated by White professors and dismissed by others. Further, they expressed a feeling of not being "good enough" because of their ethnicity (Alexander \& Hermann, 2016). In addition, students expressed the need for mentorship and improved image for black males in society (Scott et al., 2013).

Career counseling could inform prospective students about the nature of the careers they show interest in and could outline the difficulty and rigor of the associated course of study. Research shows that students that get career counseling and have role models will 
be better prepared for their initial college major (Russell \& Russell, 2015). Similarly, academic advising is identified as an area in need of major improvement (Lancaster \& Yonghong, 2017). Proper influencers see themselves as providing psychological and practical support, and students' advisors play a key role in choosing science classes (Sherman-Morris \& McNeal, 2016).

Peer Support. Lack of peer interactions between various ethnicities as well as positive and negative interactions with same race peers, both inside and outside educational institutions, can have a major impact on future decisions to enroll in STEM majors (Strayhorn, 2010). If, in college, a student does not see peers, teachers or professors of a similar race, their self-efficacy may be compromised in a way that will impact retention and overall success. If a group possesses ethnic diversity in their proximal peer group, the members of that group are more likely to experience positive STEM outcomes, elevated levels of self-efficacy, and strong intentions to pursue and finish STEM degrees (Hall et al., 2017). Hall et al. (2017) also comments on the importance of peer support in mitigating the negative effects of discrimination and prejudice. Similarly, Lancaster and Yonghong (2017) state that peer support will mitigate the obstacles in the path to academic success. On the other hand, being a unique individual in a class or set of classes could present one with the need to approach existing social cliques (Alexander \& Hermann, 2016). The dilemma could create a feeling of isolation and seclusion. Having a supportive peer group can prove helpful by providing useful suggestions and approaches to problems (Gasman et al., 2017).

Self-Efficacy. Self-efficacy is described as confidence in one's ability to effectively execute courses of action needed to succeed in particular situations (Haynes \& Jacobson, 2015). One manifestation of diminished self-efficacy is not feeling smart or prepared enough (Scott \& Martin, 2014). This feeling can influence decisions to enroll in a program of study related to a particular field as well as negatively impact pursuit of a STEM major (Samuels \& Seymour, 2015). Strayhorn (2010) identified professors' negative perceptions about underrepresented minority students' decisions to pursue STEM majors or careers, along with lack of support and role models in natural science, as factors that could bring about a decrease in persistence by underrepresented minority populations majoring in STEM. A sense of isolation in relation to other members of the group, in addition to feelings of being different and being an imposter, may affect one's sense of self-efficacy, which has been linked to depression, anxiety, and low STEM performance (Robinson et al., 2016).

Negative experiences in school with peers and professors have been shown to significantly diminish self-efficacy and confidence (Alexander \& Hermann, 2016; Strayhorn, 2015). After accounting for variables like personal, environmental, and behavioral factors, Litzler, Samuelson, and Lorah (2014) found that African Americans and Latinos showed increased confidence in STEM, even when faced with negative interactions with peers and professors. These findings indicate that external factors and self-motivation are crucial factors related to outcome experiences (Anumba, 2015). Indeed, self-motivation is related to persistence toward goals; people with weak efficacy and 
beliefs will tend to surrender to the negative aspects of the situation (Byars-Winston, 2013). Additionally, high self-efficacy is positively correlated with interest (Lent et al., 2011).

Financial Factors. Underrepresented minority students and White students face similar barriers that curtail their pursuit of STEM majors. In terms of financial barriers, underrepresented minorities are disproportionately overrepresented among students with high financial need. First-generation students of all races and ethnicities face barriers of misinformation and a lack of sound advice from family and peers about education costs, living expenses, and ways to gain access to financial aid. Financially needy students avoid getting loans out of fear of not been able to pay them back (Eichelberger, Mattioli \& Foxhoven, 2017; Haynes \& Jacobson, 2015). This cumulative disadvantage can affect decisions by underrepresented minority women to enroll in school and can also impact their financial stability in STEM fields (Kachchaf et al., 2015). In addition, Martin, Simmons, \& Yu (2013) concluded that Hispanic women do not possess sufficient family social capital and lack basic information about financial aid and college choices.

Sense of Belonging. Feeling part of a group and feeling a sense of belonging is a natural human desire; through a sense of belonging, we acquire a sense of identity, often giving us a feeling of gratification (Strayhorn, 2015). Strayhorn (2015) observed the predisposition to study in relation to student background traits, pre-college dispositions, prior achievement scores, sense of belonging, and college grade-point average (GPA) in African American students. After controlling for parents' level of education, athletic status, and fraternity membership, he found that a sense of belonging, as well as high school GPA and ACT scores, were significant in the decision to enroll in STEM. McPherson (2017) studied African American women and demonstrated the importance of interpersonal relationships with professors, instructors, and assistants to their decisions to persist until graduation. These relationships supported their stamina and persistence in STEM and for these students created a sense of belonging to STEM majors. Conversely, a negative interaction with a professor could affect the sense of belonging in STEM fields (Strayhorn, 2010). Collectively, these studies imply that positive enriching experiences with professors, supportive family members who motivate them, positive experiences with peers, and being surrounded by encouraging people of the same ethnicity and diverse ethnicities, all work to enhance a sense of belonging in STEM for minority students.

Commitment to Diversity. Not only does segregation in schools causing a damaging effect on STEM persistence, but so does limited diversity in faculty members and the absence of diverse role models in higher education (Peralta et al., 2013). Many STEM programs focus only on increasing the representation of underrepresented minority students but lack the willingness to tackle institutional issues such as racism and sexism and also lack appropriate role models for underrepresented minority students (Linley \& George-Jackson, 2013). Grossman and Porche (2014) report that, despite support from teachers and parents, discrimination was the salient barrier for many high school underrepresented minority students pursuing a STEM major. To increase diversity, it is recommended that more school activities be offered while encouraging parents and 

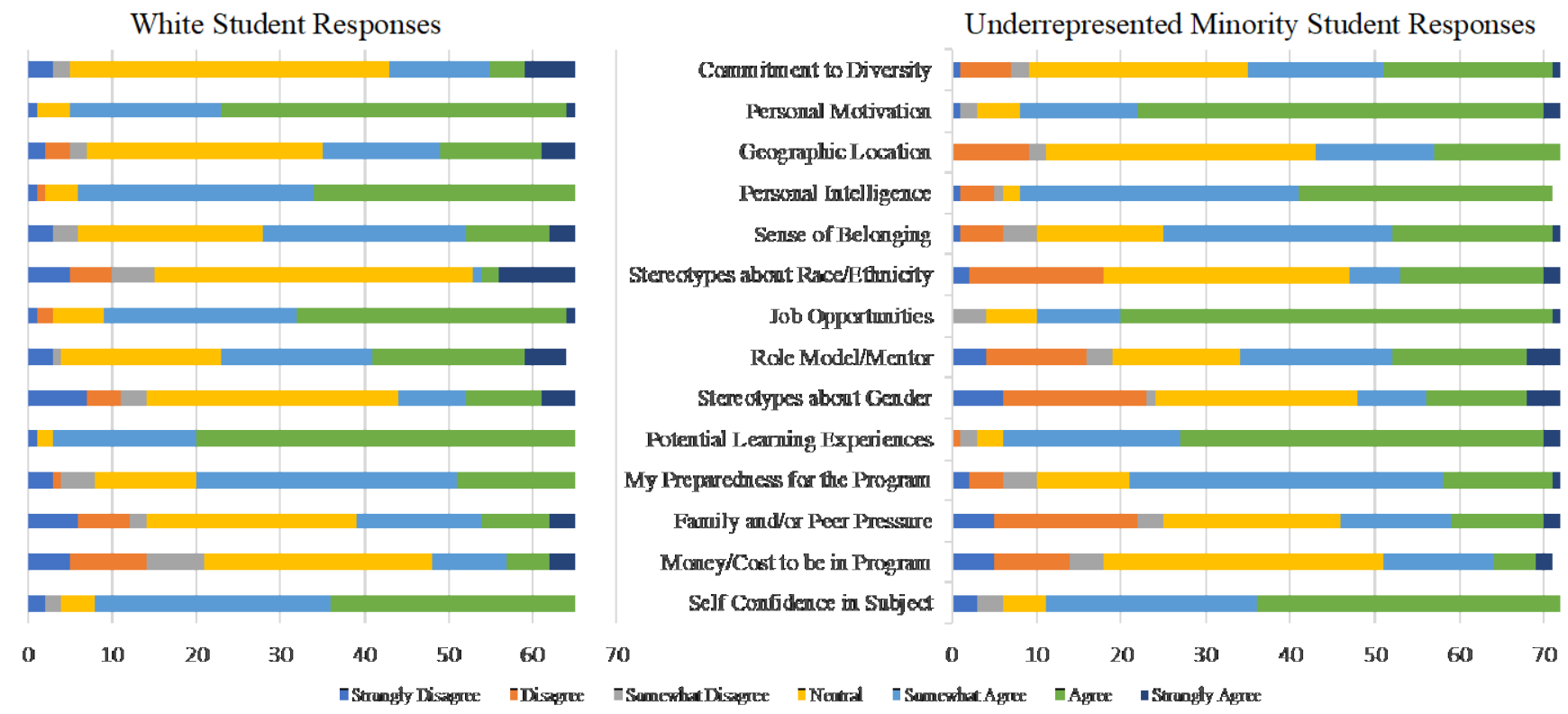

Figure 2. Student responses about influences on remaining a biology major shown by race/ethnicity.

children to participate. Diversity has been shown to be an effective tool to address social discomfort; to this end, it is necessary that the majority of the student body actively engage with students of varying ethnicities (Major, Fletcher, Streets, \& Sanchez-Hucles, 2014).

\section{Methodology}

Hispanic-serving institutions (HSI) are defined as institutions of higher education whose enrollment of full-time undergraduates includes at least $25 \%$ Hispanic students. We sought to address two research questions in this study: (1) Which of the factors identified in the published literature do students identify as affecting their decision to persist in a STEM major?, and (2) Are there differences between White and underrepresented minority students in their perception of the importance of these factors?

For the purpose of this pilot study, we e-mailed all students majoring in biology at a Texas HSI and from the respondents recruited a convenience sample of 137 biology majors to complete a questionnaire regarding factors affecting their decision to persist in a STEM major. This reliable ( $\alpha=0.78), 14$-item Likert scale questionnaire identifies factors cited in the literature that might influence students' decisions to remain enrolled in their STEM major, with a scale ranging from 1, strongly disagree (made me not want to remain) to 7, strongly agree (made me want to remain). We also collected demographic data such as birthdate, race and ethnicity (White (not Hispanic), Black or African American, Hispanic 


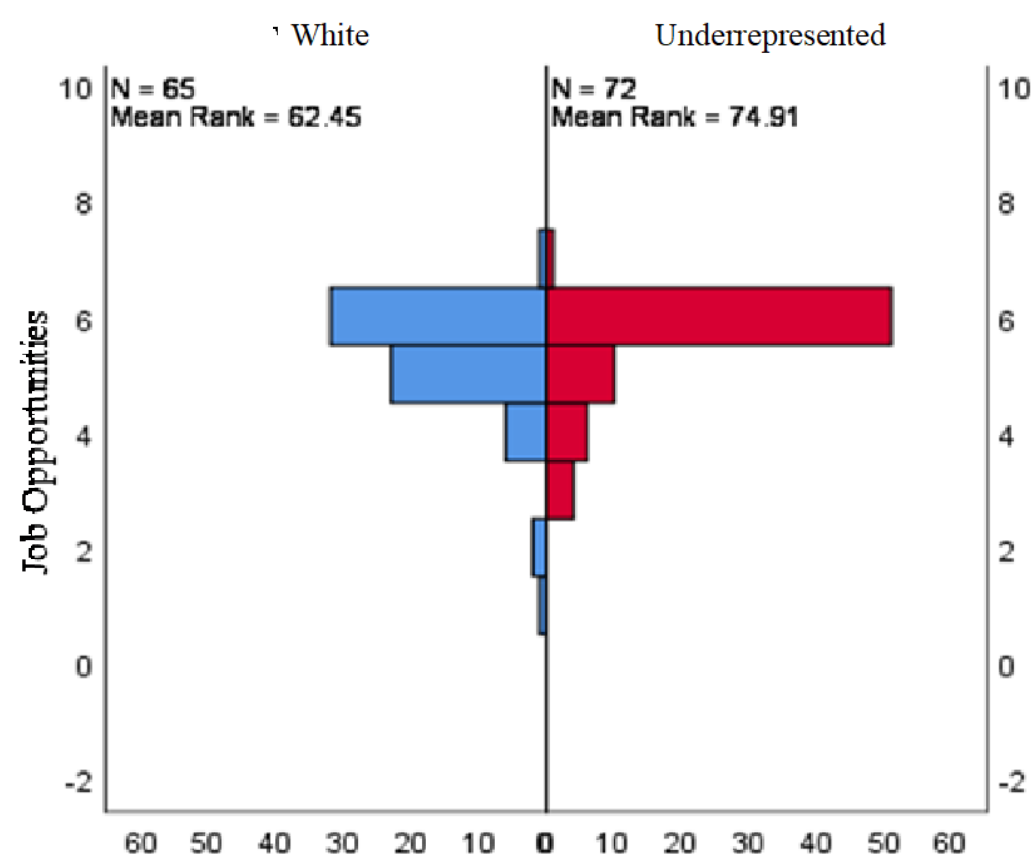

Figure 3. Independent samples Mann-Whitney U Test evaluating job opportunities as a factor influencing persistence in a biology degree program by race/ethnicity.

or Latino, Asian, American Indian or Alaska Native), sex, U.S. citizenship, highest degree attainment, parents' highest degree attainment, languages spoken, hometown zip code, major or program of study, and current grade level. We compiled all data to calculate descriptive statistics for the item responses. A Mann-Whitney U test was used to identity significant difference between responses of White $(n=65)$ and underrepresented minority $(\mathrm{n}=72)$ students.

\section{Results}

Overall, students indicated the strongest factors related to their decisions to remain enrolled were: Personal Motivation, with $67.2 \%$ of respondents saying they agree or strongly agree, Potential Learning Experiences, with $65.7 \%$ of respondents saying they agree or strongly agree, and Job Opportunities, with $62.0 \%$ of respondents saying they agree or strongly agree. The least influential factors on students' decisions to remain enrolled were Family and/or Peer Pressure and Stereotypes about Gender, both having $24.8 \%$ of respondents saying they disagree or strongly disagree that these issues influenced their decision to stay enrolled in their biology program. When we separated participants with respect to race/ethnicity (Figure 2), we found only one significant difference in reported influences, Job Opportunities. The mean rank for White students was 62.45 and 
Journal of Research in Technical Careers

underrepresented minority students was 74.91; the distributions in the two groups differed significantly (Mann-Whitney $\mathrm{U}=2764.5, \mathrm{n}_{1}=\mathrm{n}_{2}=12.46, \mathrm{P}=0.036$ two-tailed) (Figure $3)$. Therefore, we conclude that underrepresented minority students are significantly more influenced by Job Opportunities than White students to stay enrolled as a biology major; yet this item has a small effect size $(0.18)$. We should note that while not statistically significant, we also found that differences in reported influence for the item Role Model and Mentor was approaching significance, with the mean rank for White students being 75.17 and underrepresented minority students being 62.57 (Mann-Whitney $U=1877, \mathrm{n}_{1}$ $=\mathrm{n}_{2}=12.6, \mathrm{P}=0.056$ two-tailed).

\section{Discussion}

In relation to the modified career choice model of social cognitive career theory (Lent et al., 1994; Lent et al., 2011), our participants indicated that Personal Motivation, Potential Learning Experiences, and Job Opportunities influenced their choice actions to persist in undergraduate STEM programs. While the findings of this study should be interpreted narrowly as the sample comprised only students from a single major (biology) at a single institution (a Texas HSI), they suggest that among the factors influencing persistence, underrepresented minority students and White students differed only in the importance they placed on expected job opportunities. Strayhorn (2010) suggested that underrepresented minority students encounter a barrier to persistence in their majors due to negative statements by professors and peers, questioning the suitability of their decision to pursue STEM majors and careers. Given the importance that underrepresented minority students place on enhancing their job prospects through the pursuit of a STEM major, institutions would do well to step up both professional development opportunities for students (helping them with letters of inquiry and introduction, for example) as well as highlighting successful alumni from diverse backgrounds and with diverse trajectories.

About two-thirds of White students indicated role models and mentors (e.g., teachers, professors, family members, parents, siblings, peers) as influential in their choice to remain a biology major. As participants were not asked to specify the mentors/role models that were most influential in the survey, we infer from the literature that they likely received positive encouragement from their professors (Gasman et al., 2017) given that teachers are often seen as role models (Basile \& Murray, 2015). In contrast, only about half of underrepresented minority students in their biology major indicated they were influenced by role models and mentors. It is tempting to speculate that the difference, which approached but did not reach statistical significance, may reflect the small number of underrepresented minority STEM faculty that serve as role models. Because a paucity of role models may promote isolation and teachers tend to serve as role models, underrepresented minority STEM faculty are critical to the success of underrepresented minority students (Basile \& Murray, 2015). Other studies have also found that underrepresented minority students have articulated the necessity of mentors and role models (Kachchaf et al., 2015; Scott et al., 2013) and diverse STEM faculty (Basile \& Murray, 2015) to prepare them for STEM careers. Additionally, most STEM majors (e.g., 
DeCuir-Gunby et al., 2013; Stokes et al., 2015) have had at least one supportive family member that sparked their interest and encouraged them to pursue STEM careers.

Implications for Practice. This study was conducted at a Texas HSI and, of the underrepresented minority students in this study, most were Hispanic (52.79\%). As such, this institution is particularly oriented to providing support to Hispanic students, which may have influenced the findings. While the findings of this study are not generalizable to other institutions or ethnic groups, the implications may inform practices of STEM programs at other HSIs. To encourage underrepresented minority and Hispanic students' personal motivation to remain enrolled in STEM majors, advisors and faculty should strive to internalize positive perceptions about these students and offer additional support. Additionally, faculty should suggest informal and formal learning experiences that may enhance underrepresented minority students' successful completion of STEM coursework, and career advisors can help underrepresented minority students identify potential job opportunities. To foster a supportive learning environment and systemic institutional change, administrators can provide professional development training for faculty and advisors.

Underrepresented minority students were somewhat less likely than White students to agree with the statement "Role models made me want to remain in my major." It seems plausible that the difference could be attributed to the very small number of underrepresented minority faculty to whom students would relate. We suggest administrators continue to work to increase efforts to provide a diversity of mentoring and role models to support underrepresented minority students in undergraduate STEM programs.

Implications for Future Research. This study is part of a larger scale National Science Foundation-funded study that will examine the educational trajectories of STEM students as well as the factors that influence persistence of underrepresented minority students and White students. The findings from the final survey will be corroborated with in-depth, counter-life story (life histories that counter majoritarian perspectives) interviews to understand participants' lived experiences throughout the K-16 STEM education pipeline. Further research should be considered to examine the influence of career and technical education on STEM majors' persistence in undergraduate education and beyond.

\section{Acknowledgements}

This material is based upon work supported by the National Science Foundation (NSF) under Grant No. 1764404. Any opinions, findings, and conclusions or recommendations expressed in this material are those of the author(s) and do not necessarily reflect the views of the National Science Foundation. The authors would like to acknowledge Kelly E. Williams, Michael Paul Gutierrez Mannix, and Mairi Vannella for their contributions to this project. 
Journal of Research in Technical Careers

\section{References}

Alexander, Q., \& Hermann, M. (2016). African-American women's experiences in graduate science, technology, engineering, and mathematics at a predominantly White university: A qualitative investigation. Journal of Diversity in Higher Education, 9(4), 307-322. https://doi.org/10.1037/a0039705

Anumba, E. (2015). Successfully navigating through college: Voices of African American males. International Journal of Teacher Leadership, 6(1), 35-56.

Basile, V., \& Murray, K. (2015). Uncovering the need for diversity among K-12 STEM educators. Teacher Education \& Practice, 28(2/3), 255-268.

Brown, B., Henderson, J., Gray, S., Donovan, B., Sullivan, S., Patterson, A., \& Wagstaff, W. (2016). From description to explanation: An empirical exploration of the AfricanAmerican pipeline problem in STEM. Journal of Research in Science Teaching, 53(1), 146-177. https://doi.org/10.1002/tea.21249

Byars-Winston, A. (2013). Connecting the disconnects. Career Planning \& Adult Development Journal, 29(2), 53-63.

Covington, M., Chavis, T., \& Perry, A. (2017). A scholar-practitioner perspective to promoting minority success in STEM. Journal for Multicultural Education, 11(2), 149-159. https://doi.org/10.1108/JME-01-2016-0001

DeCuir-Gunby, J. T., Grant, C., \& Gregory, B. B. (2013). Exploring career trajectories for women of color in engineering: The experiences of African American and Latina engineering professors. Journal of Women and Minorities in Science and Engineering, 19(3), 209-225. https://doi:10.1615/JWomenMinorScienEng.2013005769

Eichelberger, B., Mattioli, H., \& Foxhoven, R. (2017). Uncovering barriers to financial capability: Underrepresented students' access to financial resources. Journal of Student Financial Aid, 47(3), 70-87.

Gasman, M., Nguyen, T., Conrad, C., Lundberg, T., \& Commodore, F. (2017). Black male success in STEM: A case study of Morehouse College. Journal of Diversity in Higher Education, 10(2), 181-200. https://doi.org/10.1037/dhe0000013

Grossman, J. M., \& Porche, M. V. (2014). Perceived gender and racial/ethnic barriers to STEM success. Urban Education, 49(6), 698-727. https://doi.org/10.1177/0042085913481364

Hall, A., Nishina, A., \& Lewis, J. (2017). Discrimination, friendship diversity, and STEM-related outcomes for incoming ethnic minority college students. Journal of Vocational Behavior, 103(part B), 76-87. https://doi.org/10.1016/j.jvb.2017.08.010

Haynes, N., \& Jacobson, S. (2015). Barriers and perceptions of natural resource careers by minority students. Journal of Environmental Education, 46(3), 166-182. https://doi.org/10.1080/00958964.2015.1011595

Kachchaf, R., Ko, L., Hodari, A., \& Ong, M. (2015). Career-life balance for women of color: Experiences in science and engineering academia. Journal of Diversity in Higher Education, 8(3), 175-191. https://doi.org/10.1037/a0039068

Lancaster, C., \& Yonghong, J. X. (2017). Challenges and supports for African American STEM student persistence: A case study at a racially diverse four-year institution. Journal of Negro Education, 86(2), 176-189. https://doi.org/10.7709/jnegroeducation.86.2.0176

Lent, R. W., Brown, S. D., \& Hackett, G. (1994). Toward a unifying social cognitive theory of career and academic interest, choice, and performance. Journal of Vocational Behavior, 45(1), 79-122. https://doi.org/10.1006/jvbe.1994.1027

Lent, R. W., Lopez, F. G., Sheu, H. B., \& Lopez, A. M., Jr. (2011). Social cognitive predictors of the interests and choices of computing majors: Applicability to underrepresented 
students. Journal of Vocational Behavior, 78(2), 184-192.

https://doi.org/10.1016/j.jvb.2010.10.006

Linley, J., \& George-Jackson, C. (2013). Addressing underrepresentation in STEM fields through undergraduate interventions. New Directions for Student Services, 2013(144), 97-102. https://doi.org/10.1002/ss.20073

Litzler, E., Samuelson, C., \& Lorah, J. (2014). Breaking it down: Engineering student STEM confidence at the intersection of race/ethnicity minority solos and non-solos. Research in Higher Education, 55(8), 810-832. https://doi.org/10.1007/s11162-014-9333-z

Major, D. A., Fletcher, T. D., Streets, V., \& Sanchez-Hucles, J. (2014). One is the loneliest number: Comparing ethnic minority solos and non-solos. Journal of Woman and Minorities in Science Engineering, 20(4), 341-358. https://doi.org/10.1615/JWomenMinorScienEng.2014008210

Martin, J., Simmons, D., \& Yu, S. (2013). The role of social capital in the experiences of Hispanic women engineering majors. Journal of Engineering Education, 102(2), $227-$ 243. https://doi.org/10.1002/jee.20010

McPherson, E. (2017). Oh, you are smart: Young, gifted African American women in STEM majors. Journal of Women and Minorities in Science and Engineering, 23(1), 1-14. https://doi.org/10.1615/JWomenMinorScienEng.2016013400

Moakler, M., \& Kim, M. (2014). College major choice in STEM: Revisiting confidence and demographic factors. Career Development Quarterly, 62(2), 128-142. https://doi.org/10.1002/j.2161-0045.2014.00075.x

National Science Board (2015). Revisiting the STEM workforce: A companion to science and engineering indicators 2014. Arlington, VA: National Science Foundation.

O'Brien, L., Blodorn, A., Adams, G., Garcia, D., \& Hammer, E. (2015). Ethnic variation in gender-STEM stereotypes and STEM participation: An intersectional approach. Cultural Diversity \& Ethnic Minority Psychology, 21(2), 169-180. https://doi.org/10.1037/a0037944

Peralta, C., Caspary, M., \& Boothe, D. (2013). Success factors impacting Latina/o persistence in higher education leading to STEM opportunities. Cultural Studies of Science Education, 8(4), 905-918. https://doi.org/10.1007/s11422-013-9520-9

Robinson, W. H., McGee, E. O., Bentley, L. C., Houston, S. L., \& Botchway, P. K. (2016). Addressing negative racial and gendered experiences that discourage academic careers in engineering. Computing in Science \& Engineering, 18(2), 29-39. https://doi.org/10.1109/MCSE.2016.38

Russell, M., \& Russell, J. (2015). Black American undergraduate women at a PWI: Switching majors in STEM. Negro Educational Review, 66(1-4), 101-125.

Samuels, K., \& Seymour, R. (2015). The middle school curriculum: Engineering anyone? Technology and Engineering Teacher, 74(6), 8-12.

Scott, A., \& Martin, A. (2014). Perceived barriers to higher education in science, technology, engineering, and mathematics. Journal of Women and Minorities in Science and Engineering, 20(3), 235-256. https://doi.org/10.1615/JWomenMinorScienEng.2014006999

Scott, J., Taylor, K., \& Palmer, R. (2013). Challenges to success in higher education: An examination of educational challenges from the voices of college-bound black males. Journal of Negro Education, 82(3), 288-299. https://doi.org/10.7709/jnegroeducation.82.3.0288 
Sherman-Morris, K., \& McNeal, K. (2016). Understanding perceptions of the geosciences among minority and nonminority undergraduate students. Journal of Geoscience Education, 64(2), 147-156. https://doi.org/10.5408/15-112.1

Stokes, P., Levine, R., \& Flessa, K. (2015). Choosing the geoscience major: Important factors, race/ethnicity, and gender. Journal of Geoscience Education, 63(3), 250-563. https://doi.org/10.5408/14-038.1

Strayhorn, T. (2010). Work in progress - Social barriers and supports to underrepresented minorities' success in STEM fields. Frontiers in Education Conference, 2010, S1H-1. https://doi.org/10.1109/FIE.2010.5673227

Strayhorn, T. (2015). Factors influencing black males' preparation for college and success in STEM majors: A mixed methods study. Western Journal of Black Studies, 39(1), 45-63.

Whitney, D., Gammal, B., Gee, B., Mahoney, J., \& Simard, C. (2013). Priming the pipeline: Addressing gender-based barriers in computing. Computer, 46(3), 30-36. https://doi.org/10.1109/MC.2013.40 